\title{
Research on Numerical Modelling in Lake Dynamics
}

\author{
E.Thinakaran, PD.Arumairaj
}

\begin{abstract}
Lakes are natural water bodies, where flow from single or various rivers is impounded by a natural impediment. Lake water environmental problem has severe effect on human health and the socio-economic sustainable development. So, it's very important to find the more effective way of controlling the water pollution. Dynamics of lakes is the vast topic, which includes important concepts such as circulation of lakes, pollutant transport and interaction between lakes and hydrology. The hydrological dynamics of lake has been influenced by land cover modification, climate change, and increase in population and development activities within the catchment. Due to less velocity, lake impounds water for some time, and a significant characteristic of a lake is its retention time. Wind is the prevalent force in driving the circulation and in developing turbulent mixing in the lakes. Vertical mixing is caused by this turbulence. During circulation, summer and winter has different wind patterns. Strong wind would cause storm surge, which results in increased, mixing and transport in the surface water systems. Air temperature influence surface waters through heat flux and evaporation exchange between the air and the water. The Coriolis force is certain in large lakes due to earth rotation. Precipitation, tributaries inflow, runoffs, etc are lake water inputs. During numerical simulation of lakes, generally Boussinesq approximation and hydrostatic approximation are considered due to actual density distribution variations in water depth concepts respectively. It is essential to calibrate and verify the model before predictive applications anywhere. A simple numerical hydrodynamic model of a lake includes wind stress, bottom friction, Coriolis force, inflow, outflow, and the bottom topography of the lake. The hydrodynamic model has to be tested for stability, convergence, and sensitivity to parameters such as wind shear, wind direction, and vertical eddy viscosity effects. In this paper, the numerical simulation of lake dynamics has been discussed in detail.
\end{abstract}

Keywords: Numerical simulation, Lake Dynamics, Circulation of Lakes, Model: Calibration \& Verification.

\section{INTRODUCTION}

For the past five decades, lake dynamics have been in the important hotspot in the field of water environment research. The study of lake water quality has grabbed considerable attention because of its atmospheric and ecological importance. The quality of lake also affects the groundwater quality [7]. Climate change is already started to influence the plants and animals that exist in freshwater lakes and rivers [16]. Inter-governmental Panel on Climate Change (IPCC) anticipate the increases in world's average surface temperature of 1.4 to $5.8^{0} \mathrm{C}$ in 2100 [12].

Numerical simulation is the effective way to predict the flow pattern and pollutant transformations within the lake. Most commonly used numerical techniques are Finite Difference Method (FDM) and Finite Element Method

Revised Manuscript Received on July 18, 2019.

E.Thinakaran, Research Scholar, Karunya Institute of Technology and Sciences (Deemed to be University), Coimbatore, T.N, India

PD.Arumairaj, Professor, Karunya Institute of Technology and Sciences (Deemed to be University), Coimbatore, T.N, India
(FEM) in lake modelling. Finite Difference Method is a traditional numerical method of computation, which is represented by a rectangular grid or orthogonal curvilinear grid to the computed area. Every computed variables are arranged on a grid node and differentiate to approximate. Even though FDM has some limitations, it can be overcome by advanced mesh generation techniques, proposed boundary coordinates fitting method, etc [15]. In this paper numerical simulations of lake dynamics model along with pollutant transport has been reviewed.

\section{CIRCULATION OF LAKES}

Review of numerical modelling of large-scale wind driven circulation in lakes was explored by Cheng et al, 1976. The governing equations which detail this motion are discussed along with the suitable numerical techniques need to solve them in lakes. The numerical simulation models can be primarily classified into: the layered models, the Ekman-type models, and the other three-dimensional models. Lake surface temperature (LST) is the most important factor in the precipitation pattern over the lake. Sun, et al, 2015, applied a coupled atmosphere-lake model, which consists of the Weather Research and Forecasting (WRF) model and the Princeton Ocean Model (POM) to understand LST over the lake. Sensitivity analysis had been done for the selection of an optimum mix of physics options including cumulus, microphysics, and planetary boundary layer schemes for simulating precipitation over the lake. Podsetchine et al, 1999, formulated the hydrological sub component of the Lake Tanganyika Research (LTR) Program, blending computer modelling and field measurements. The objective of this modelling work is to compute the role of the important factor affecting water currents in the lake and to comprehend the peculiarities of spatial and temporal variations of its hydrophysical characteristics. Wind-induced shear stresses is the the main driving force of the lake dynamics. Beletsky et al, 1999, depicted the mean circulation in 100 lakes with longterm current observations for 20 years. This information is essential for addressing ecological and management issues, since it provides a hint of transport pathways of nutrients and contaminants on longer time scales. Zhang et al, 2007, comprehend the current observations into a two-dimensional circulation model of the lake, based on the Princeton Ocean Model (POM) and steered by observed winds. While surface level measurements are not available, appropriate covariance models of this stream function, the current updates are calculated by kriging interpolation using the observations and the corresponding model forecast.

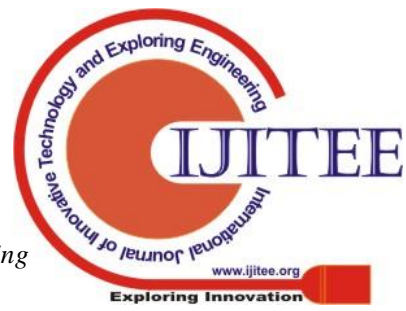


A three-dimensional general circulation model has been developed to estimate mixing processes in the lake with icecovered for a certain time. The impacts of spatial patterns of snow and ice transparency on circulation pattern and temperature are investigated. Generated temperature profiles comply well with in situ measurements and specifically successful in simulating mixing processes in the lake. Ice covered simulations are density driven [13]. Beletsky and Schwab, 2001, applied 3D primitive equation numerical model to analyze the seasonal and inter-annual variability of circulation and thermal framework in the lake. Large-scale circulation patterns tend to be counter clockwise with cyclonic circulation within each sub-basin. The largest currents and maximum cyclonic vorticity develop in the fall and winter when temperature gradients are less, but wind stresses are strongest. The smallest currents and minimum cyclonic vorticity develop in spring and summer when temperature gradients are more, but wind stresses are weakest. A 3D primitive equation numerical ocean model was used to simulate hydrodynamic conditions during the sediment resuspension event in the lake due to storm winds up to $20 \mathrm{~m} / \mathrm{s}$. Hydrodynamic model results utilizing the meteorological model winds as the driving function exhibited significant improvement over model results which were based on observed winds proving the importance of mesoscale winds for current modelling in large lakes [5]. Pal et al, 2017, analyzed the circulation pattern in lake during the wind flow. The previously established wind induced three dimensional lake circulation numerical models has been applied to the lake, where a typical sigma co-ordinate system was applied for the bathymetry of the lake more precisely. Simulation results were compared with measured velocity profile of the lake and the analysis reports a fair agreement between them. Ibrahim and McCorquodale, 1985, simulated the hydrodynamics of the transporting flow as well as the transformation processes of the pollutant in the lake, using the numerical model. Before prediction applications of the model, it should be calibrated and verified. The hydrodynamic model which includes wind stress, bottom friction, Coriolis force, inflow, outflow, and the bottom topography of the lake has to be developed and verified with field data. The hydrodynamic model was tested for stability, convergence, and sensitivity to parameters such as wind shear, wind direction, and vertical eddy viscosity effects. The lake circulation patterns for different steady state wind and ice conditions have been generated. The depth average velocities were used in a finite element pollutant transport model. An upwind finite element formulation was used to get a stable solution for the convective transport phenomena. Simulated pollutant concentration was compared with the observed field data and fairly good agreement was found. Research done by various modellers indicates the importance of circulation of lakes in the concept of lake dynamics.

\section{POLLUTANT TRANSPORT \& RESULTS}

Pollutant transport of lake is done using structured discretization of the geometry of lake, together with the finite difference method (FDM) and the finite elements method (FEM). Hydrodynamic model (HD) incorporates Navier-Stokes and pressure equations in FDM and connected with the fourth order Runge-Kutta numerical scheme [18]. In the velocity flow of hydrodynamic field, pollutant transport model with advective and diffusive processes has been associated. Numerical scheme for transport model is resolved by semi discrete formulation of FEM. Rahaman and Andallah, 2014, simulated using advection diffusion equation incorporating explicit central difference scheme in space and forward difference method in time. Zabadal et al, 2006, proposed a new analytical method for solving 2D advection-diffusion equation depicting the dispersion of bacteria and chemicals in lakes and rivers. This method results in low processing time, while comparing with available experimental data. Application of Environmental Fluid Dynamic Code (EFDC) model and numerical source-apportionment model to predict the contributions of various pollution sources to the lake at any time and position exhibits good results. The observed hydrodynamic and water-quality parameters of lake for one year have been considered for both calibration and validation. Pollution-control plan can be implemented by optimizing the pollution load reduction in the lake.

Ferhat et al, 2014, proposed the physical basis and the mathematical detail of the various components of the climate system and the derivation of differential equations which describe the most important climatic processes. The modelling of the horizontal transport of pollutant has been done by considering the basic assumptions for the wind velocity, mass burning rate of pollutant from the source. Concentration in horizontal direction of flow of pollutant has also done. Leon and Escalante, 1993, simulated the flow patterns and pollutant transport in lake by considering, three different FDM computational models [22]. The different models are (a) explicit scheme in rectilinear coordinates without convection, (b) implicit scheme in rectilinear coordinates including convection, and (c) implicit scheme in curvilinear coordinates including convection. These models were assessed for inter-calibration purposes contemplating account convection, wind and bottom stresses, Coriolis forces and balance between inflow and outflow in the lake. Johari et al, 2017, modelled a 1D advection diffusion equation for predicting the pollution concentration transport. Implicit Crank Nicolson scheme has been used in approximating the advection diffusion equation. Bai et al, 2018, presented effective on the optimization of pollution load reduction in the lake and can be utilized to evaluate the most useful implementation of its pollution-control plan. Results are used to forecast the transportation of water pollution concentration by employing the velocity and diffusion parameters.

Andreadakis et al, 2003, applied EUTRO-SEL (Eutrophication-Dissolved Oxygen Mathematical Model) to analyze the three water management scenarios to describe the good water quality with acceptable minimum operational water level in the lake. The water level of $786 \mathrm{~m}$ ensures very good water quality characteristics pertaining to the recent standards and trends within the European Commission. Jing and Kang, 2017, simulated source-sink 
term in water temperature models exemplify the net heat absorbed or released by the lake. Source-sink term is very significant in lakes, because it considers solar radiation which affects water temperature. A vertical one-dimensional heat conduction equation depicts the water temperature changes adopting two-step operator-splitting method. Romeiro et al, 2017, analyzed the concentration of biochemical oxygen demand, $\mathrm{BOD}_{5}$ to evaluate the water quality of the lake. The numerical simulation was done by aid of discretization in curvilinear coordinates of the geometry of lake, combining with FDM and FEM. The performance of the proposed model for water quality was performed by comparing the experimental values with the numerical results. Numerical outcome identifies the pollutant sources, optimal treatment for the recovery and betterment of the society.

\section{CONCLUSION}

Finite Difference Method and Finite Element Method are the effective way to simulate lake dynamics. The paper detailed about the input data, parameters to be considered and numerical techniques to be adopted for the lake flow and pollutant transport. This paper also shows the two important aspects such as circulation and pollutant transport to be considered in simulating the dynamics of lake. To obtain the accuracy in the numerical model, advanced numerical schemes are to be incorporated in the model.

\section{REFERENCE}

1. Andreadakis A, Noutsopoulos $\mathrm{C}$ and Gavalaki G, "Assessment of the Water Quality of Lake Plastira through Mathematical modelling for alternative management scenarios", Global Nest Journal, 2003, Vol. 5, Issue. 2, pp 99105.

2. Bai H, Chen Y, Wang D, Zou R, Zhang H, Ye R, Ma W and Sun Y, "Developing an EFDC and Numerical SourceApportionment Model for Nitrogen and Phosphorus Contribution Analysis in a Lake Basin", Water, 2018, Vol. 10, Issue. 1315, DOI: 10.3390/w10101315.

3. Cheng RT, Powel TM and Dillon TM, "Numerical models of wind-driven circulation in lakes", Applied Mathematical Modelling, 1976, Vol 1, pp $141-159$.

4. Beletsky D and Schwab DJ, "Modeling circulation and thermal structure in Lake Michigan: Annual cycle and interannual variability, Journal of Geophysical Research, 2001, Vol. 106, pp 19,745-19,771.

5. Beletsky D, Schwab DJ, Roebber PJ,McCormick MJ, Miller GS and Saylor JH, "Modeling wind-driven circulation during the March 1998 sediment resuspension event in Lake Michigan”, Journal of Geophysical Research, 2003, Vol. 108, DOI:10.1029/2001JC001159.

6. Beletsky D, Saylor JH, and Schwab DJ, "Mean Circulation in the Great Lakes", Journal of Great Lakes Research, 1999, Vol. 25, Issue. 1, pp 78-93.

7. Bhateria R AND Jain D, "Water Quality ASSESSMENT OF LaKe Water: A ReVIEW", Sustainable Water Resources Management, 2016, Vol. 2, Issue. 2, PP $161-173$.

8. Ferhat M, Bensaada S and Bouziane M T, "Discretization in space for an atmospheric pollution model with finite difference method application in region South Algeria", Journal of Ecosystem \& Ecography, 2014, Vol. 4, Issue. 3, DOI: $10.4172 / 2157-7625 . S 1.018$.

9. Ibrahim KA and McCorquodale JA, "Finite element circulation model for Lake st. Clair", Journal of Great Lakes Research, 1985, Vol. 11, Issue, 3, pp 208-222.
10. Jing $\mathrm{Z}$ and Kang L, "High-order scheme for the source-sink term in a one-dimensional water temperature model", Plos One, 2017, Vol. 12, Issue. 3, DOI:10.1371/journal.pone.0173236.

11. Johari H, Rusli N and Yahya Z," Finite Difference Formulation for Prediction of Water Pollution, IOP Conference Series: Materials Science and Engineering, 2017, Volume 318, conference 1, DOI: 10.1088/1757$899 X / 318 / 1 / 012005$.

12. Houghton JT, Ding Y, Griggs DJ, Noguer M, Vander Linden PJ and Xiaosu D, "Climate Change 2001: The Scientific Basis Contribution of Working Group I to the Third Assessment Report of the Intergovernmental Panel on Climate Change (IPCC)", 2001, Cambridge University Press, Cambridge.

13. Lawrence SP, Hogeboom K and Le Core HL, "A threedimensional general circulation model of the surface layers of Lake Baikal”, Hydrobiologia, 2002, Vol. 487, pp 95-110.

14. Leon LF and Escalante M, "Flow and pollutant transport in Lake Chapala, Mexico", Transactions on Ecology and the Environment, 1993, Vol. 2, pp 279-286.

15. Li Q, Zhang Q and NAN HY, "Study on Numerical Simulation Model of Lake Water Quality", International Conference on Environment, Climate Change and Sustainable Development (ECCSD 2016), Beijing, China, 2016, May 28 29, ISBN: 978-1-60595-358-8.

16. Mooij WM, lsmann SH, De Senerpont Domis LN, Nolet BA, Bodelier PLE, Boers PCM, Pires LMD, Gons HJ, Ibelings BW, Noordhuis R, Portielje R, Wolfstein K and Lammens EHRR, "The impact of climate change on lakes in the Netherlands: a review, Aquatic Ecology, 2005, Vol. 39, pp 381-400, DOI 10.1007/s10452-005-9008-0.

17. Pal M, Roy MB and Roy PK, "Wind Induced Lake Circulation Model Application in the Lake Rudrasagar, Tripura (India)", European Journal of Advances in Engineering and Technology, 2017, Vol. 4, Issue. 5, pp 404409.

18. Pardo SR, Natti PL, Romeiro NML and Cirilo ER, "A modeling of the carbon-nitrogen cycle transport at Igapó I Lake - Londrina, Paraná, Brazil", Acta Scientiarum. Technology, 2012, Vol. 34, Issue. 2, pp 217-226.

19. Podsetchine V, Huttula $T$ and Savijärvi $H$, "A three dimensional-circulation model of Lake Tanganyika", Hydrobiologia, 1999, Vol. 407, pp 25-35.

20. Rahaman MM and Andallah LS, "Simulation of Water Pollution by Finite Difference Method", International Journal of Research in Information Technology, 2014, Vol. 2, Issue, 1,pp 17-24.

21. Romeiro NML, Mangili FB, Costanzi RN, Cirilo ER and Natti PL, "Numerical simulation of BOD5 dynamics in Igapó I lake, Londrina, Paraná, Brazil: Experimental measurement and mathematical modelling", Semina: Exact and Technological Sciences, 2017, Vol. 38, Issue. 2, DOI: 10.5433/1679-0375.2017v38n2p50.

22. Smith GD, "Numerical Solution of Partial Differential Equations: Finite Difference Methods", Oxford University Press, 3rd. Edition, 337 p., 1985.

23. Sun X, Xie L, Semazzi FHM, and Bin Liu, "A Numerical Investigation of the Precipitation over Lake Victoria Basin Using a Coupled Atmosphere-Lake Limited-Area Model", Advances in Meteorology, 2014, Vol.2014, http://dx.doi.org/10.1155/2014/960924 